\title{
Horn Gore Enterocele in Bullock
}

\author{
E. Kalaiselvan*, Swapan Kumar Maiti, G.V. Prakash, Sharun Khan, \\ S. Shivaraju and Naveen Kumar
}

Division of Surgery, ICAR-Indian Veterinary Research Institute, Izatnagar, Bareilly, Uttar Pradesh, India

*Corresponding author

\section{A B S T R A C T}

\section{Keywords}

Hernia, Trauma,

Bullock,

Prosthetics,

Polypropylene mesh

Article Info

Accepted:

22 June 2020

Available Online:

10 July 2020
A 5 Year old bullock presented with the history of horn gore trauma on right flank region and not passed dung since last 5 days. On palpation intestinal loops were palpable like clumsy feel on right flank just beneath skin. With this we diagnosed tentatively the case as traumatic hernia. On exploration of right flank laparotomy confirmed muscle rupture and mild peritonitis. The rent was supported by outlay tethering of polypropylene mesh size 6"× 8". The muscle and skin closed with simple interrupted pattern suture pattern. Post operative antibiotic, analgesic and indoor care maintained for 5 days. $12^{\text {th }}$ postoperative day skin suture removed and animal returned to its activity after 3 months of surgery.

\section{Introduction}

Horn gore injury leads to mild swelling to fatal death depends on severity. Hernia also reported due to horn gore injury or any physical trauma inflicting the rupture barrier of hallow organ (Senthilkumar et al., 2014). Horn gore injury abdomen may mostly have open wound along with hernia (Rani et al., 2010) due to thin muscles over flank region (Al-Sobayil et al., 2007). To the authors knowledge this is the first case report on traumatic hernia of intestine in bullock and its surgical management.

\section{Case history and clinical examination}

A $400 \mathrm{~kg}$ bullock presented to Teaching Veterinary Clinical Complex \& Referral Veterinary Polyclinic, Indian Veterinary Research Institute, Izatnagar with the anamnesis that had gore injury 5 days back. The animal right side had diffused swelling with open wound at paracoastal region. The open wound sutured by field veterinarian. Feeding habbit and defaecation was unsatisfactory. In detailed physical examination revealed right flank has muscle rupture with clumsy feeling of intestine. 
Although background and palpation of intestine suspected hernia, we failed to palpate hernia ring in both standing and lateral recumbency. Haematological examination revealed shift to left and increased packed cell volume. Biochemical parameters could not show any remarks.

\section{Surgical treatment}

\section{Preoperative care}

The animal stabilized with eight litres of normal saline, eight litres of Ringer lactate, Enroflxacin@5 mg/kg and Meloxicam @ $0.5 \mathrm{mg} / \mathrm{kg}$ body weight for 3 days (includes preemptive period). The bullock kept off fed for 48 hours with routine open wound dressing.

\section{Anaesthesia and intraoperative procedures}

The bullock anxiolysed with intravenous midazolam@0.5 mg/kg and butorphanol @ $0.2 \mathrm{mg} / \mathrm{kg}$ followed by casted on left lateral recumbency. The proposed site of surgery (right flank) prepared aseptically by removal of hair and application of antiseptic solution.

About $30 \mathrm{~cm}$ length oblique skin incision made over the swelling of right flank region. Immediately after skin incision clumsily adhered intestine was observered and inspected for any necrosis and physical obstruction. To the gross appearance no portion seems unhealthy and adherence removed wherever possible. Intestines washed with Ringers solution and reposited into the abdominal cavity. Now the ring take into consideration a big longitudinal rent was observed from 2 " behind the paracostal region to 2 " anterior to pelvic brim of pubis. The muscle fibre orientation and its insertion preclude that extensive rupture of both the obliqus abdominus transverse abdominus muscle. The edges of muscles were freshened. Anterior half of the rent musculatures came into apposition so these closed using polyamide in a horizontal mattress fashion. But posterior half of the rent doesn't come into apposition hence as much as possible muscle fibres bring close by interrupted suture pattern with negligible tissue tension. After that outlay hernioplasty over abdominus muscle had done using polypropylene mesh size 6" 68 ". The mesh was anchored on all the four sides with simple continuous pattern using polyamide in a way each side sutures were ended while before turning into another side. Subcutaneous tissues closed in ford interlocking suture pattern using polyglactin 910 suture material. Subcutaneous dead space was large and extended till right rear side of scrotum. To overcome seroma formation we applied customized infusion set drain tube made ventral to the flap of the flank. The skin was closed in cruciate pattern using polyamide. The right flank open wound edges reconstructed and sutured in a former manner.

\section{Post operative care}

Intravenous fluid therapy for 2 days, inj.Enroflaxacin @ 5mg/kg body weight intravenously BID for 5 days, inj.Flunixin@ $1 \mathrm{mg} / \mathrm{kg}$ body weight intravenously BID for 3 days, inj.Chlorpheneramine maleate $10 \mathrm{ml}$ intramuscularly OD for 3 days and inj.lignocaine @ $0.5 \mathrm{mg} / \mathrm{kg}$ body weight intravenously BID for 2 days was administered during postoperative period. Also daily flushing and suctioning of drain tube was done till no collection of seroma.

\section{Outcome}

The animal showed improvement in feeding habit and passed dung on $3^{\text {rd }}$ and $2^{\text {nd }}$ post operative day. It's advised to the owner regarding animal split, individual feeding neither house with aggressive horned animals and nor return to work for 3 months. The animal returned to normal activity after 3 months of surgery with an uneventful recovery. 
Figure.1 Posterior half of the hernial ring after repositioning of an intestine and omentum

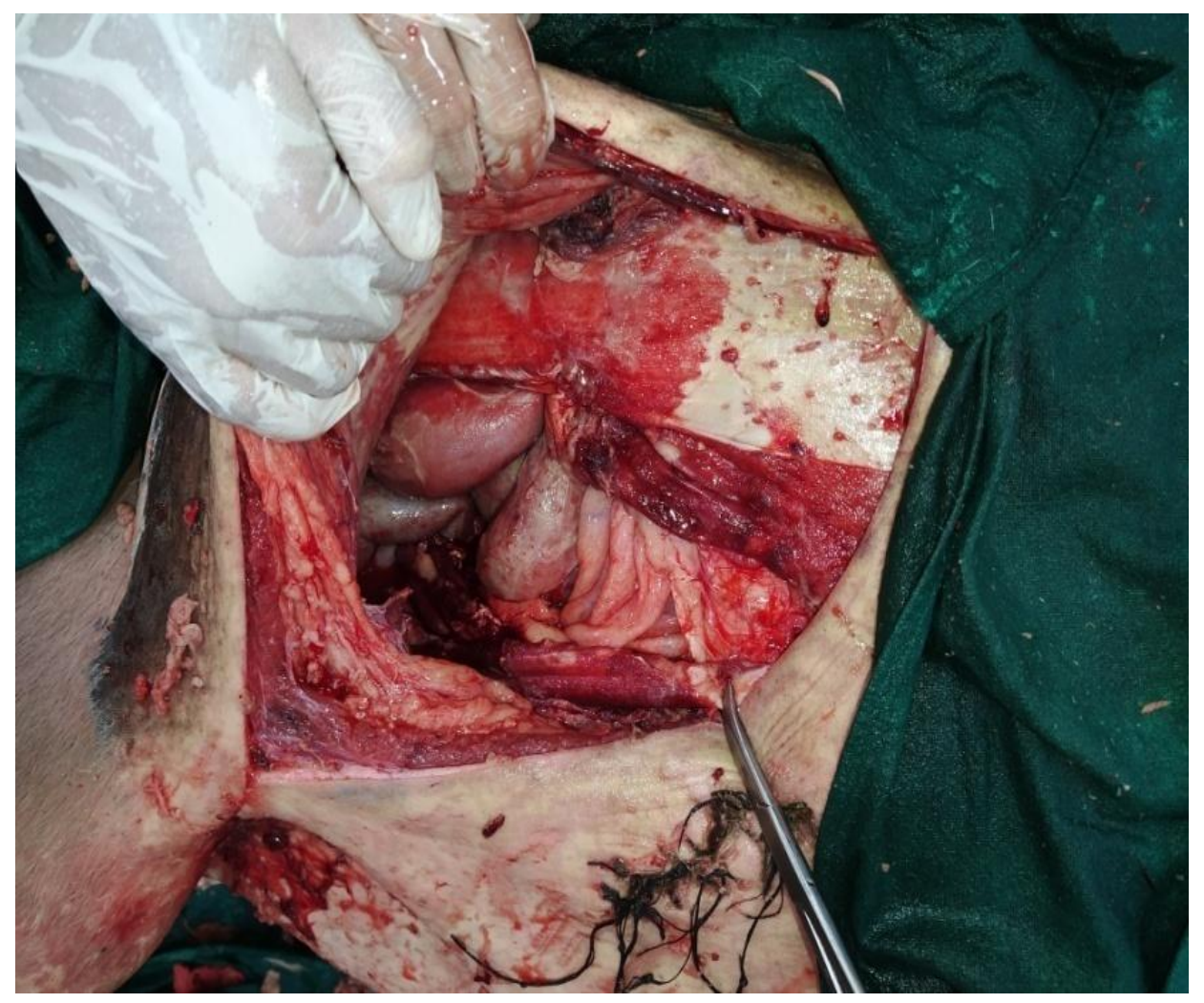

Figure.2 Outlay polypropylene mesh over and after tethered with transverse abdominus

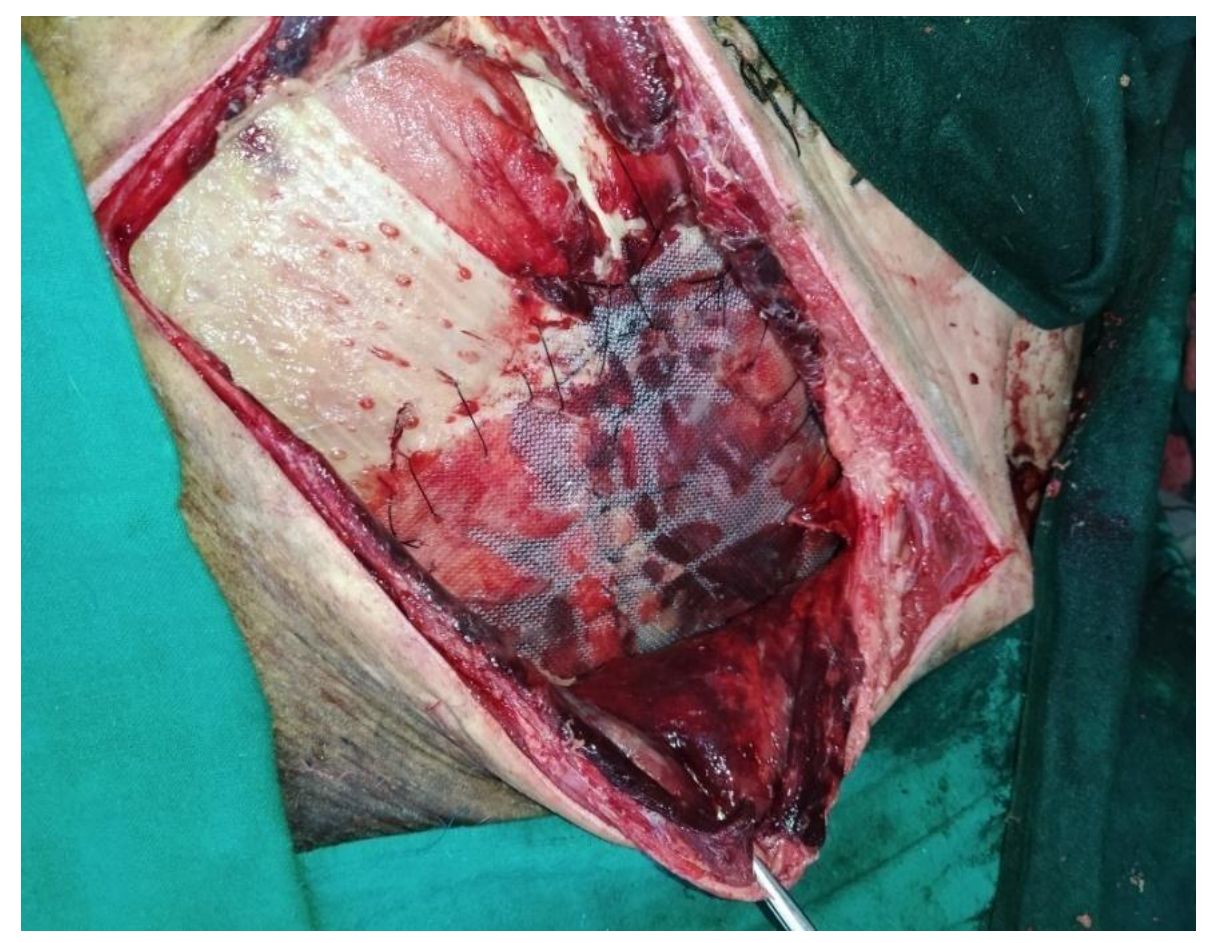


Figure.3 After complete suturing of skin and drain

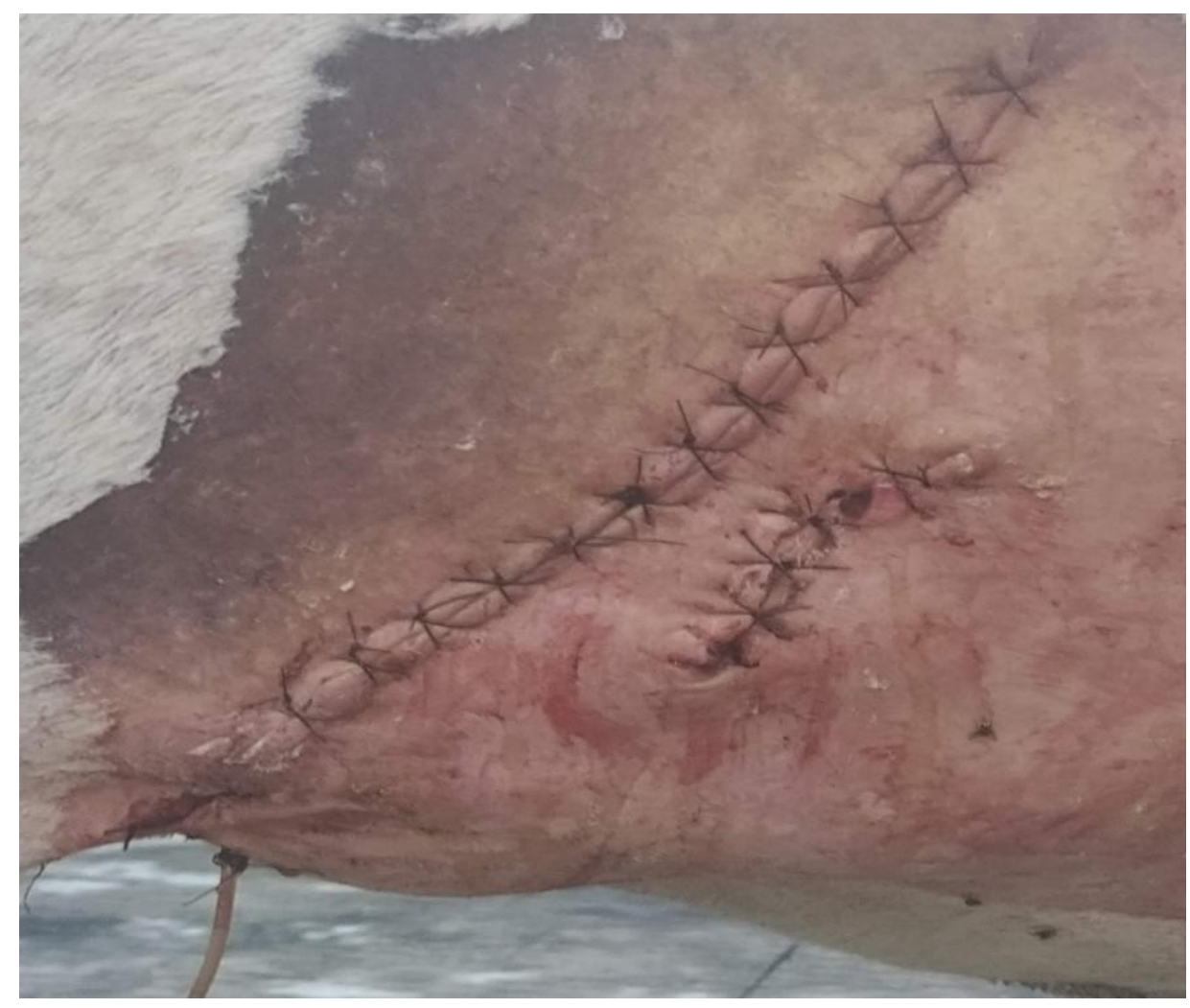

Figure.3 Bullock immediately after surgery

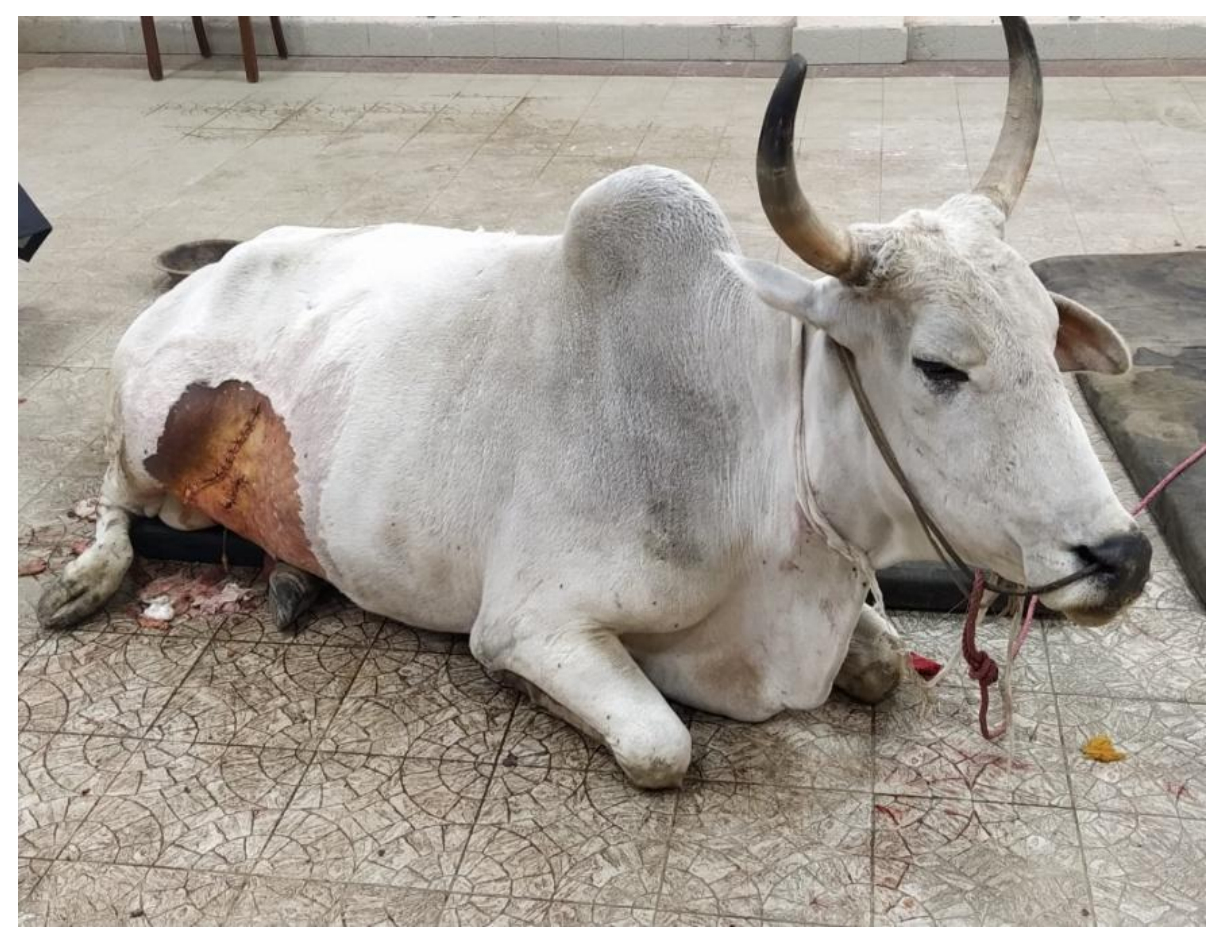


Figure.4 Seventh postoperative day

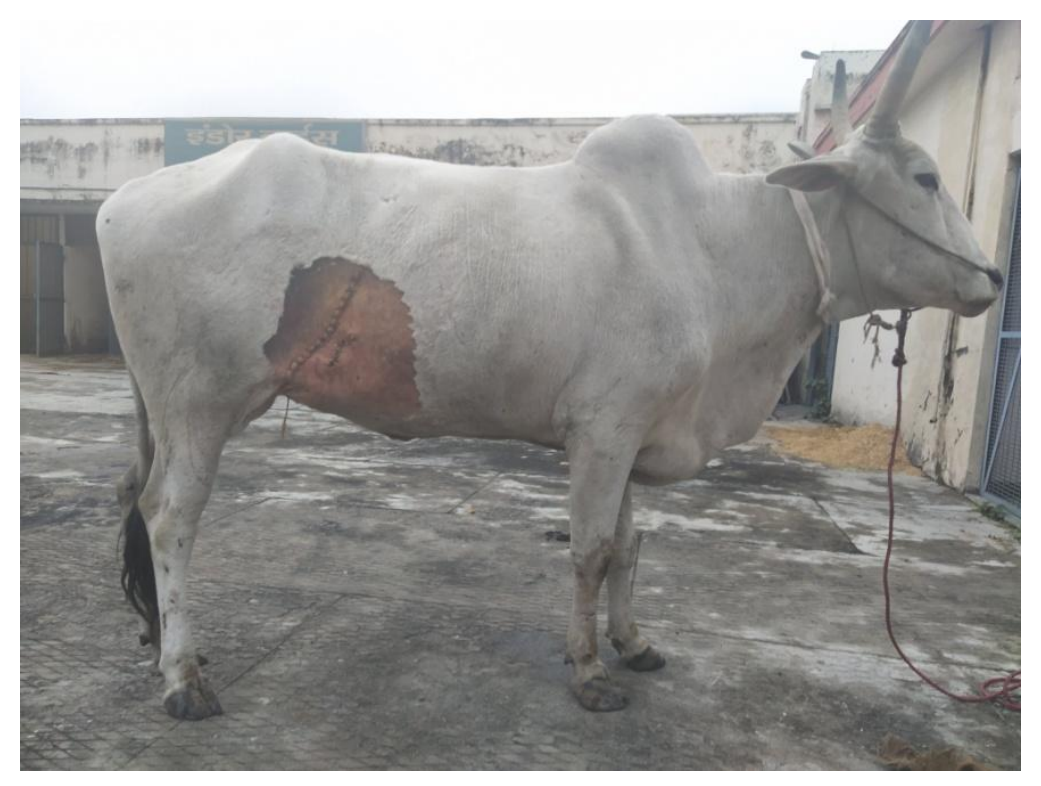

Hernia defined as passage of an organ as part or whole into an abnormal space or unnatural location either via normal or abnormal or acquired opening. Its further classified as based on development either congenital or acquired, depends on presence of hernia sac and contents either true or false and depends on manifestation either internal or external hernia. Also further hernia can be classified based on location and involvement of organ so. A true hernia must consist of three portion hernia ring, hernia sac and its contents (Pratschke, 2002). Trauma is the major cause of acquired hernia in animals. It's common in bovine when grouping of horned animals (Tijjani et al., 2015). Uncommonly by falling or automobile and pregnancy also can cause hernia. Unsightliness swellings followed by trauma, pain on palpation, palpation of ring and rarely achezia and treading of feet are clinical signs of hernia. Although physical palpation of hernia ring could confirms for hernia sometimes not possible due to adherence of hernia sac with ring and extensive herniation of organ can mast the rent. In our case also we could not palpate ring preoperatively. In such cases diagnosis via explorative surgery, radiography, ultrasonography, Computed tomography and Magnetic Resonance Imaging (MRI) will be better option (Van Hout et al., 2018 and Tenzel et al., 2018). Needle tapping of swelling could give the clue type of organ at the same time it must be differentiated from others abscess, cyst, tumour and haematoma. Treatment of hernia has a three basic principles orderly reposition of an organ in its anatomical location, reconstruction a of hernia ring and avoid recurrence. In reposition if rent is small kelotomy (enlarging the hernia ring or rent) and the organ must be healthy if not surgical resection, while reconstruction depends on rent size and strength either herniorrhaphy (suturing of hernia ring) or hernioplasty (use of prosthetics or biomaterials to close hernia ring) (Kumar et $a l ., 2014)$, similarly avoidance of recurrence by control of existing and possible future causes. Conservatively some asymptomatic small hernias managed by elastic band application (Freeman, 2005) and infiltration of irritant like tincture iodine around the rent. Mosbah and Abouelnasr, (2015) used cotton fabric for the repair of hernia in ruminants. But polypropylene has good results use in ruminants (Raghunath et al., 2017). Outlay 
application of prosthetic mesh has low complication rate due to avoidance of prosthetic mess contact with visceral organs (Kassem et al., 2014). Doxycycline administration enhancing hernia repair outcomes using popypropylene mesh. it reduces MMP and increases collagen 1 to 3 ratio (Tharappel et al., 2017). Silk fibroin hydrogel with polypropylene mesh prevents of post hernia adhesion (Konar et al., 2017). Use of double sheet of mesh shows superior to single in the treatment of hernia (Elce et al., 2005). In our case single sheet used dueto economical concern over livestock. Application of mesh and extensive dead space produces large quantity of seroma (Raghunath et al., 2017). So drain advocated in the cases of hernia. Hernia has large extensive rupture of muscle and prepubic tendon rupture questionable outcome (Kumara et al., 2017). It's concluded in our case although extensive rupture use of bioprosthetic with the meticulous postoperative care brings a successful recovery of patient.

\section{References}

Al-Sobayil FA, Ahmed AF (2007). Surgical treatment for different forms of hernias in Sheep and Goats. Journal of Veterinary Science, 8: 185-191.

Elce Y.A., Kraus B.M., Orsini J.A., 2005. Mesh hernioplasty for repair of incisional hernias of the ventral body wall in large horses, Equine vet. Educ. 17 (5): 252256

Freeman, D.E., 2005. Management of ventral incisional hernias in large horses: a surgical challenge. Equine veterinary education, 17(5), pp.247-251.

Kassem, M.M., El-Kammar, M.H., Korittum, A.S. and Abdel-Wahed, A.A., 2014. Using of polypropylene mesh for hernioplasty in calves. Alexandria Journal of Veterinary Sciences, 40(1), pp.112-117.
Konar, S., Guha, R., Kundu, B., Nandi, S., Ghosh, T.K., Kundu, S.C., Konar, A. and Hazra, S., 2017. Silk fibroin hydrogel as physical barrier for prevention of post hernia adhesion. Hernia, 21(1), pp.125-137.

Kumar, N., Mathew, D.D., Gangwar, A.K., Remya, V., Muthalavi, M.A., Maiti, S.K. and Sharma, A.K., 2014. Reconstruction of large ventrolateral hernia in a buffalo with acellular dermal matrix: a method for treating large hernias in animals. Veterinarski arhiv, 84(6), pp.691-699.

Kumara, S.R., Sagar, R.S., Maruthi, S.T., Banakar, P.S. and Kumar, K.P., 2017. Caesarian Section for Management of Hysterocele-A Report of Two Cows. Intas Polivet, 18(2), pp.437-438.

Mosbah,E. and Abouelnasr, K.S. (2015). Commercial polyester/cotton fabric (Damour) - A novel prosthetic material for Hernioplasty in ruminants. Iranian Jr. Vet. Res. 16: 105-09

Pratschke, K., 2002. Management of hernias and ruptures in small animals. In Practice, 24(10), pp.570-581.

Raghunath, M., Sagar, P.V. and Ravikumar, P., 2017. Hernioplasty using Polypropylene Mesh for Surgical Management of Ventral Hernia in a Crossbred cow. Intas Polivet, 18(2), pp.381-383.

Rani M, Rohit SA, Dikshit PC (2010). Injuries by Bull Horns: Patterns and Prevention Protocols. Anil Aggrawal's Internet Journal of Forensic Medicine and Toxicology, 11: 1-26.

Senthilkumar S, Madan M, Mahesh MS (2014). Bull Gore injury- Its impact and surgical management. International Journal of Biomedical and Advance Research, 5: 279-280

Tenzel, P., Bilezikian, J. and Hope, W.W., 2018. Diagnostic Tools in Hernia Disease. In The Art of Hernia Surgery 
(pp. 31-39). Springer, Cham.

Tharappel, J.C., Harris, J.W., Totten, C., Zwischenberger, B.A. and Roth, J.S., 2017. Doxycycline alters collagen composition following ventral hernia repair. Surgical endoscopy, 31(4), pp.1659-1666.

Tijjani, A.N., Muhammad, A.S., Mohammed, K., Abba, Y., Teik, E.L.T.C.L., Adamu, L., Osman, A.Y., Saharee, A.A., Lila, M.A.M., Haron, A.W. and Abdullah, F.F.J., 2015. Management of horn gore injury and urticaria in a dairy cow: A case report. Journal of Advanced Veterinary and Animal Research, 2(3), pp.366-368.

Van Hout, L., Bökkerink, W.J.V., Ibelings, M.S., Heisterkamp, J. and Vriens, P.W.H.E., 2018. Outcomes of surgery on patients with a clinically inapparent inguinal hernia as diagnosed by ultrasonography. Hernia, 22(3), pp.525531.

\section{How to cite this article:}

Kalaiselvan, E., Swapan Kumar Maiti, G.V. Prakash, Sharun Khan, S. Shivaraju and Naveen Kumar. 2020. Horn Gore Enterocele in Bullock. Int.J.Curr.Microbiol.App.Sci. 9(07): 32363242. doi: https://doi.org/10.20546/ijcmas.2020.907.377 